\title{
Experiments with Distributed Theatre
}

Doug Williams and Ian Kegel BT Research \& Innovation

Pablo Cesar and Jack Jansen Centrum Wiskunde \& Informatica (CWI)

Marian Ursu University of York

Erik Geelhoed Falmouth University t was September 2014; it was my [Doug Williams] daughter's 13th birthday. I was in Cornwall, clapping furiously in appreciation of the marvelous performances of a troupe of actors with whom I had been working intensively for the previous 10 days and with whom, in an on-and-off way, we all had been working for about a year. You should have been there.

This moment of applause was the culmination of an effective and enjoyable collaboration between a theatre troupe and a team of technologists. As an affectionate shorthand, we referred to ourselves as "luvvies and techies." Both teams were full of talented individuals who happened to speak different languages, both desperately trying to understand what the other wanted. And in the end, we succeeded. As the artistic director Bill Scott commented, "communication was really good on this project; it was fantastic."

The troupe in Cornwall, the luvvies, were Miracle Theatre Company-a small, well-established regional company touring both familiar and new work across England. They aim to bring theatre to people, often performing in small outdoor locations using simple staging, lighting, and props. We had been working with them on the production of a performance of Shakespeare's The Tempest, but this was not a straightforward performance. Miracle advertised it as "The Tempest Shaken \& Stirred! One theatre company. One play. Two venues. Two completely different, yet shared experiences" (see Figure 1).

The distributed performance took place in two theatres with three audience groups. There was an audience in each performance location and a third set watching an online version streamed over the Internet (see Figure 2). The actors communicated between the two stages using an experimental multicamera video conferencing system, whose key components are described elsewhere. ${ }^{1-3}$ This system automatically framed camera views in real time and, for the two performance spaces, rendered images onto screens that were built into the sets. A third rendition was then created for the home viewer. All the video and audio signals traveled via a server in London, covering 300 miles to link the two stages, which were located approximately 300 yards apart.

We, the techies, were part of a European project, Vconect (www.vconect-project.eu), which was working to improve ad hoc video calling between groups. This performance allowed us to work in a situation where groups of people, the theater troupe, needed to communicate naturally. The location, Cornwall, with its accelerated deployment of high-speed fiber broadband, let us find locations that had access to the new $80 \mathrm{Mbps}$ service. What opportunities, wondered the Miracle Theatre Company, might these technologies offer?

\section{Embracing Digital Technology}

According to its website (www.miracletheatre. co.uk), Miracle aims to
Produce a rich mix of touring theatre, always with a unique comic style, joyful use of language and an immediate visual appeal. It embraces digital technology and nurtures new writers, performers, venues and promoters. Miracle works [to] build audiences by bringing 'big' shows to little venues; it is committed to touring work which is innovative, but not intimidating, to communities in the far flung corners of the UK.

Our technologies, while neutral toward comic style, use of language, and visual appeal, offer significant opportunities with respect to bringing "big shows to little venues" and delivering "innovative work" to the "far flung corners of the UK." The motivation for this work was thus to establish how consumer-grade broadband, cameras, and projection technologies could be used to deliver an engaging and amusing performance to a paying audience. We also wanted 
to explore the extent to which it could extend audience reach, bring something new to the theatre, and even hint at new forms of creative artistic expression.

The play we used (The Tempest) was the company's summer production and had been performed all over the southwest of England. Set on a remote island where a magician (Prospero) lives with his daughter Miranda, having been exiled there by his younger brother Alonso, Prospero and Miranda share the island with Ariel, a nymph-like spirit, and Caliban, a magical monster, both of whom Prospero controls. Prospero, a student of the liberal arts (magic) senses that his brother is sailing past the island and conjures the eponymous tempest that shipwrecks Alonso, the King (with whom Alonso is traveling), and a number of their acolytes. The plot centers on Prospero who, using magic, exposes his brother's dishonest ascent to power and yet chooses to forgive him. It is filled with beautiful language and many comedic passages.

In our production, the cast was split between the two locations but together they delivered a single performance mediated by the cameras, broadband, and projection technologies. This idea had an immediate appeal to Miracle's artistic director as he envisaged being able to "give an extra dimension to the production of The Tempest by placing Prospero into some quite dramatic natural surrounding-like a cliff with the sea pounding behind him ... and having the rest of the play taking place in a theatre with Prospero there on a screen and gently transporting the theatre to an environment that you wouldn't normally be able to do" (see Figure 3). This vision, while still valid, was moderated during the development stage (for more information, see www.youtube.com/watch?v=GXEcJX1LIbg).

Another motivation was to explore how the technology could allow the creative team to emphasize the nature and capabilities of the characters. Prospero, for example, can be seen as an eccentric, slightly reclusive but immensely powerful and ultimately benevolent, even Godlike, character. This was something the artistic director tried to emphasize using close-ups of Prospero's face, which were then projected to fill the screen and peer down on his beloved daughter Miranda (see Figure 4).

Ariel's magical qualities were also emphasized through the use of a double and welltimed action that made it seem that as Ariel disappeared from the screen in one location,

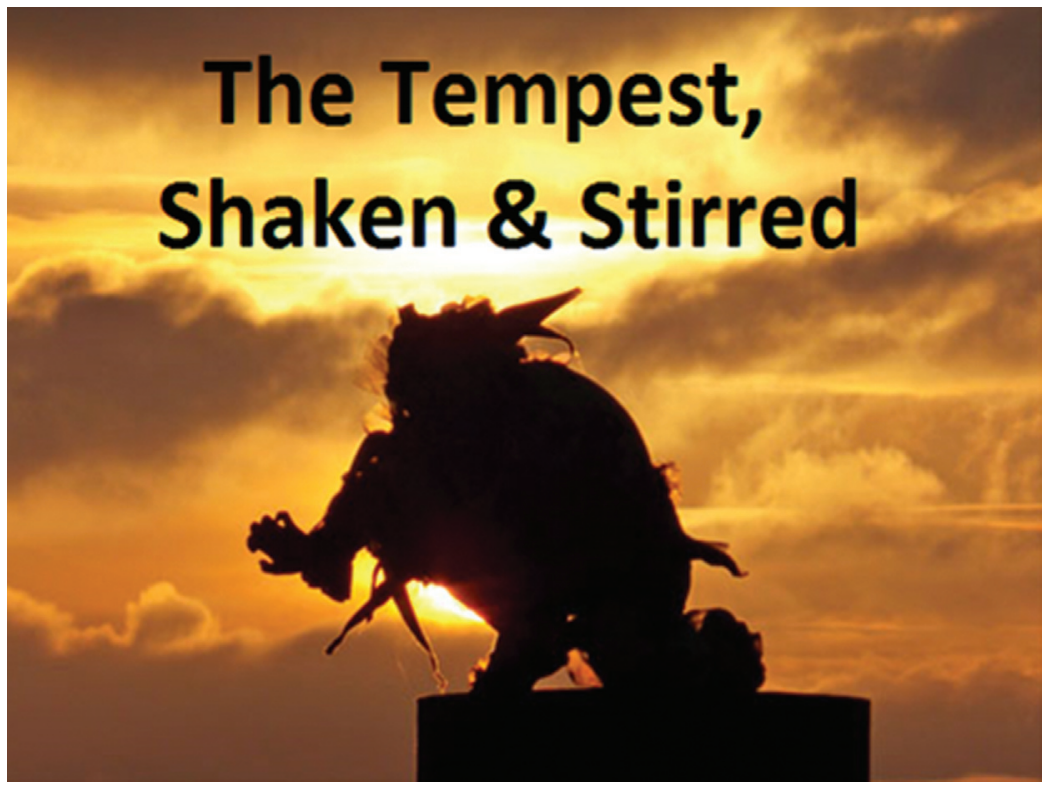

Figure 1. Catherine Lake (as Ariel) photographed during the touring performance of The Tempest by Miracle Theatre Company. This image was used to promote the distributed performance that took place toward the end of the touring run. (Source: Kirsten Prisk; image used with permission.)

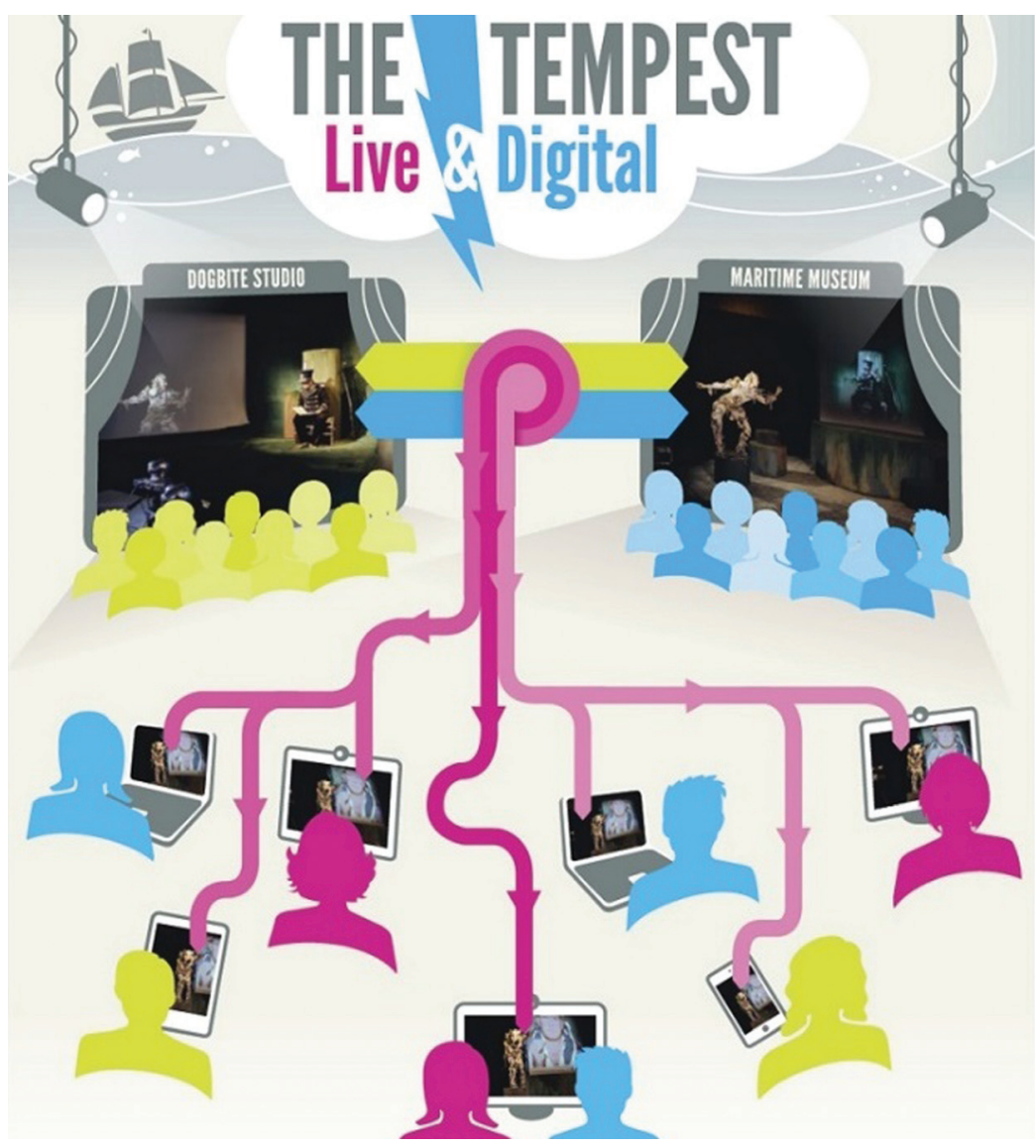

Figure 2. Schematic of the performance challenge; two performance spaces and an audience at home. 

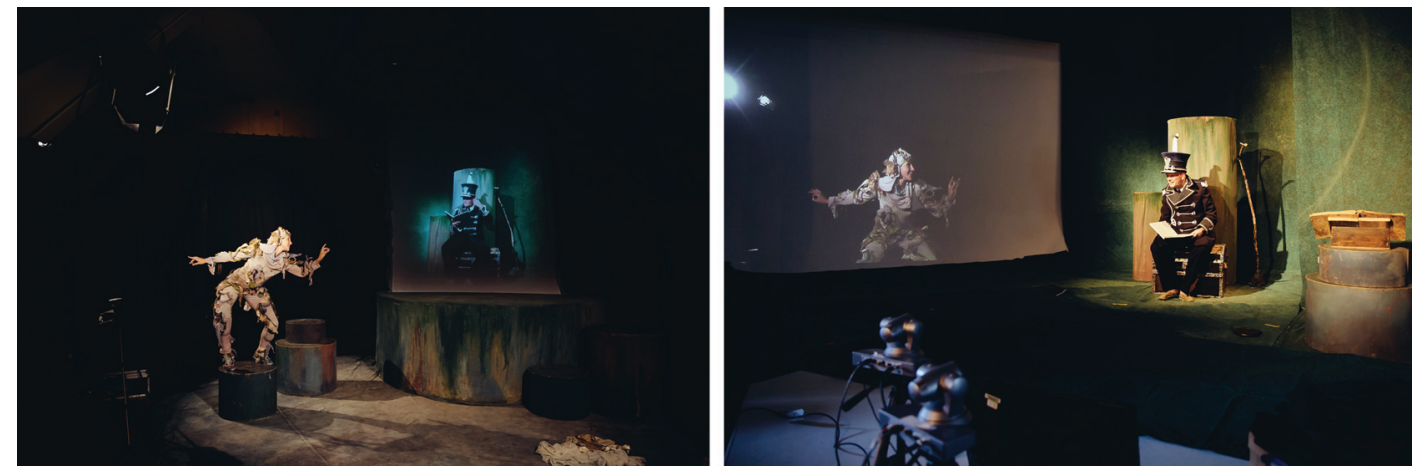

Figure 3. A single scene from The Tempest from each of the two performance locations showing Catherine Lake (as Ariel) and Angus Brown (as Prospero). (Source: Kirsten Prisk; images used with permission.)

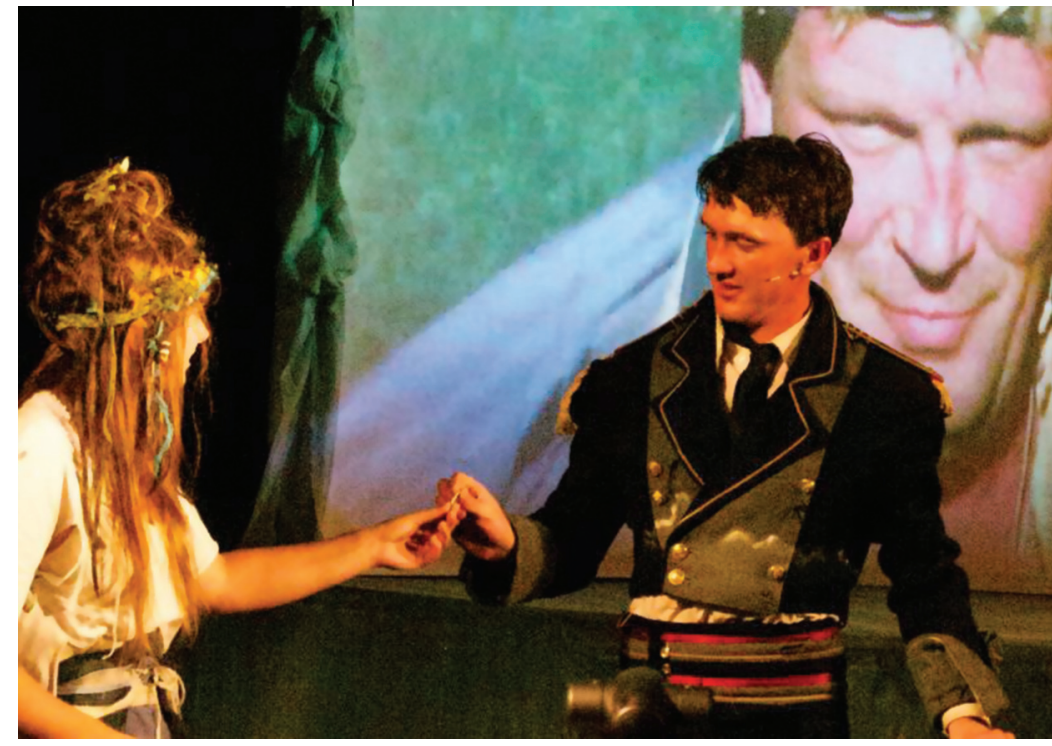

Figure 4. Left to right: Hannah Stevens (as Miranda), Ciaran Clarke (as Prince Ferdinand), and Angus Brown (as Prospero), showing how the close-up of Prospero helps convey a God-like omnipotence.

she "magically" appeared in person in the other location.

There have been many distributed productions, such as Dimanche Rouge (https://dimancherouge.wordpress.com), Skype Duet (http:// per-aspera.net/en/skype-duet), and others, ${ }^{4-6}$ but this one used two technical approaches that set it apart.

\section{Exploiting Consumer-Grade Broadband}

The first was to use consumer-grade broadband connectivity-highlighting that the transformative potential of fast connectivity is rapidly becoming available to everyone. This should affect the way theatre companies think about the art of the possible.
Scientifically, the use of consumer products places a constraint on the design. Others have achieved distributed performances using gigabit networks ${ }^{7}$ that mean video compression is unnecessary. This gives access to lower intrinsic roundtrip times, reducing the effective delay between venues. Such approaches are, for the moment, not a solution to Miracle's desire to take theatre to the people, given few people, particularly in rural communities, have access to academic and experimental networks such as JaNet and Internet2. The solution we derived was based on a series of lab-based experiments and prior knowledge that allowed us to design an architecture, and each of the respective components, to deliver good quality video (HD 720 p) encoded with an acceptably low delay.

In our case, we encoded video at about 2 Mbps and had a one-way video delay of 320 ms (the audio delay could have been shorter but we needed audio and video synchronization). From the performers' viewpoint, this setup was very good. They compared it favorably with their experiences with proprietary systems which were often dogged with much higher delays that made interaction very difficult. Indeed, the system afforded such natural interactions that, as Scott recalled, "people started behaving as if they were in the same room very quickly. When you're in down time, they all start fooling around, telling jokes, teasing each other-that sort of thing-as if they were in the same space."

\section{Experimenting with Camera Views}

The second novel approach was the method used to select the camera views for transmitting images between the two locations. Theater is (obviously) scripted. This changes significantly 
the way we think about how to choose which camera angles to select for transmission.

In live systems used to represent unscripted video communications (like meetings), complex algorithms can be developed that dynamically determine how best to represent the conversation. ${ }^{3}$ But in theatre, the director can select in advance the best camera shots. This is similar to film, where the action is scripted, but also has similarities to live television where there is no "take 2"; as such the production team had to develop a filmic language based on a limited number of possible camera views, selected live during the performance (see Figure 5).

The precise timings of events in theatre change from night to night, even if the sequence should not. For this reason, a system had to be developed that would control the cameras, moving them in sync with the theatrical script so that they framed the action in the way that the director viewed was best for the audience (see Figure 6).

There was thus a requirement for tools that can take a theatrical script and link it, via a set of cues, to editable audiovisual representation instructions. These instructions exist as a script, which can be executed by a system that we called the Performance Orchestration Engine. The system depended on a number of linked components and capabilities, described next.

Programmable cameras. We used a set of Pan/ Tilt/Zoom cameras that could be programmed to move to a range of pre-set positions. Although we didn't try this, it should be possible to use methods to automatically control the location of the cameras within the theatreeither using tracks, dollies, cranes, or even a Spidercam.

A set of composition layouts. These layouts determine where (on which screens and in which locations) live streams of content will be displayed and how they will be augmented, accompanied, or enhanced using visual effects or with additional pre-recorded media.

A script editor. A software tool needed to create a description of the way the play should be represented for the audience in each locationfor example, "Main screen venue 1, close up of Miranda from stage left." We call this description the representation script. Representation scripts are read and edited by operators and also

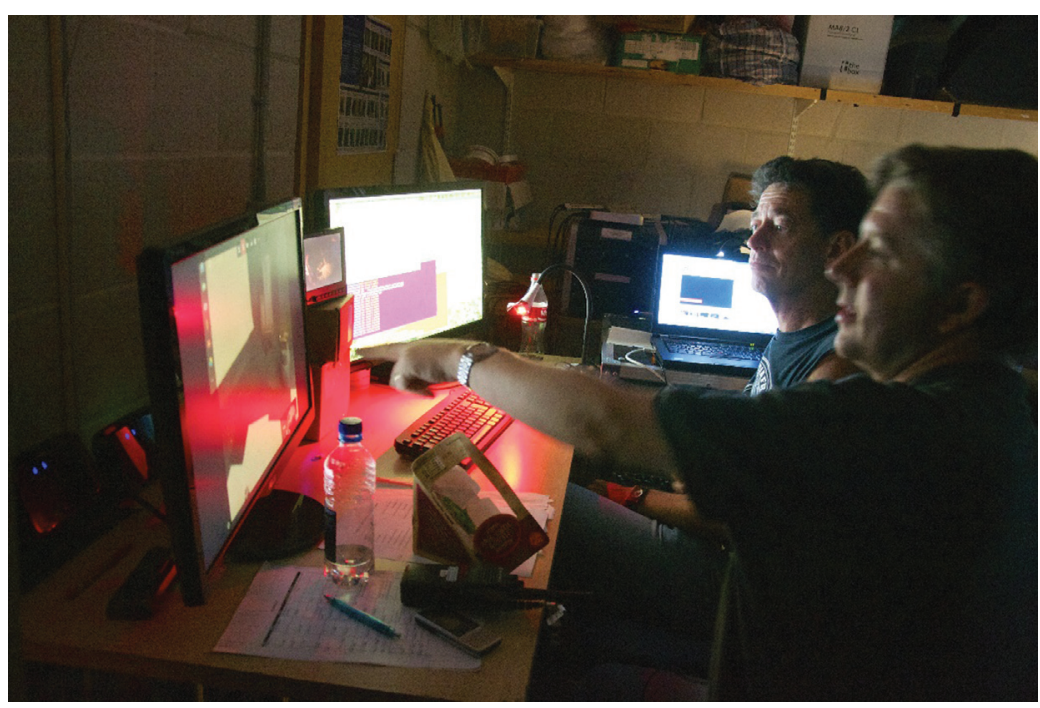

Figure 5. Jack Jansen and Ian Kegel ("geeks in the cupboard") overseeing some of the technical operations.

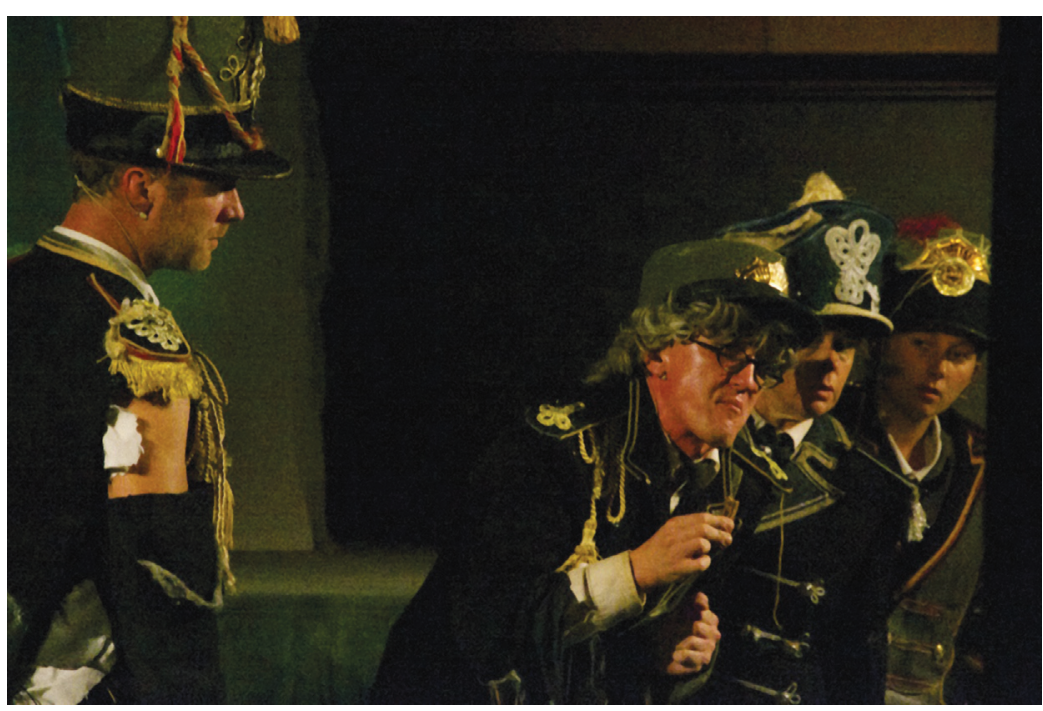

Figure 6. Ben Dyson (as Alonso), Ciaran Clarke (as Gonzalo), Lisa Howard (as Antonio), and Hannah Stevens (as Sebastian) capturing a camera view that provided a more filmic representation of the play than that experienced by the local audience.

executed automatically by the sync control component.

A sync control component. This is operated live on the night and provides means for a person following the script to synchronize the representation script with the action script (what is happening on the stage). Naïvely the techies originally thought this could be operated 


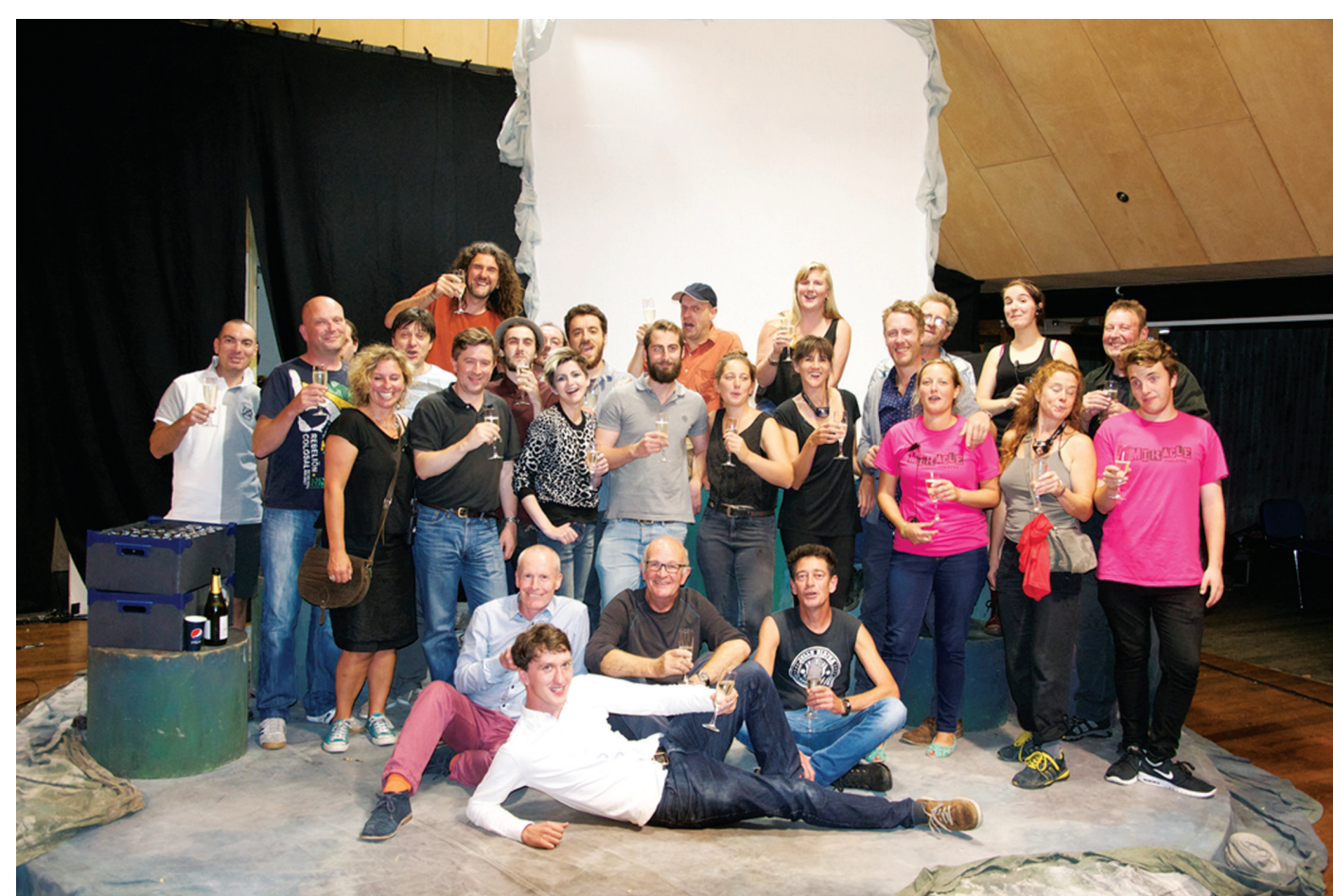

Figure 7. The team, the "luvvies and techies" from the Miracle Theatre Company and Vconect project, enjoying brief celebration before tearing down the set.

automatically against a rigid time line. Those who really knew theatre, the luvvies, gently explained that would not be the case.

Visual composition engines. These engines control both what is captured, by sending instructions to the cameras, and what is shown on the screens at each location, using layouts and stream selection. They are under the control of the sync control component. Late in the process we understood that additional screens were required; the screen equivalent of audio monitors, these showed the actors on one stage how they were appearing on the remote stage.

The overall system, the Performance Orchestration Engine, needed one operator only and yet enabled us to use mixtures of live and recorded media and to dynamically switch layouts in a scripted fashion for multiple types of endpoints (in our case, the screens on each stage and the screens at home) independently. It is, in particular, the ability of this system to render to multiple outputs simultaneously that sets it apart. Skype and Google, with help from services like Ustream Producer or LiveStream Producer, might get close, but only for one output. Our system can manage an almost arbitrarily large number of independent outputs, though we limited ourselves to three; one for each stage and one for the home audience.

\section{Expecting the Unexpected}

Throughout the development of this play, the theatre company had communicated with its audience with a tagline "expect the unexpected," and expectations were again set when Scott, during his introduction to the performance, wryly commented, " ... given the large numbers of computers involved, I shall be bold. I will not say that something may go wrong, I shall say something will go wrong."

Remarkably, given the known jeopardy, this daring distributed performance of The Tempest to a paying audience worked. The play suffered only one short stoppage and this was because a microphone was not switched on; it did not materially affect people's enjoyment of the play. As the general manager of Miracle commented: "I could not believe that when we came to do the actual thing, it literally worked the whole time, when it hadn't gone for more than about 15 minutes in all the run-ups."

And the audience seemed to like it too. The performance gave us the chance to explore what 
makes distributed performances work or not. We determined that a key metric is the ability of audience members to immerse themselves in the remote action. Exactly what breeds that immersion is less precisely known, but we postulate it is a curious coming together of direction, action, luminance, and representation.

$\mathrm{T}$ his experiment with distributed theatre worked artistically, but The Tempest was never meant to be performed from two locations. Scott ruminated some months after the event that the possibilities the technology conveyed were intriguing, but demanded, he felt, original stories written in ways that justified the use of a distributed cast. If such plays emerge, then a system like we developed-the compute power for which can already be housed in a flight case-could enable genres of performances in which the cast perform in widely distributed and small locations like village squares, pubs, and clubs, provided each location has access to a broadband connection and could project the action from the remote locations for a local audience to enjoy (for more information, see www.youtube.com/watch? $\mathrm{v}=\mathrm{O}-\mathrm{VJPv}$ rm4-8).

That this system worked functionally is a credit to the techies who built the system. That the performance worked, was enjoyable, and created the urge to clap, was a credit to the luvvies. That luvvies and techies were brought together like this, well, some credit is also due to the middlemen - the managers and bureaucrats who, even if they sit on neither side of this luvvie and techie fence, they recognize that some of the most intense and fulfilling research comes from bringing together people from apparently diverse domains (see Figure 7). It's a shame if you don't believe me; you should have been there. Perhaps in the future, we can bring the experience to you too.

MM

\section{Acknowledgments}

Vconect received funding from the European Community's Seventh Framework Programme (FP7/2007-2013) under grant agreement no. ICT-2011-287760.

\section{References}

1. P.K. Cesar et al., "Toward Connected Shared Experiences," Computer, vol. 47, no. 7, 2014, pp. 86-89.
2. I.C. Kegel et al., "Enabling 'Togetherness' in HighQuality Domestic Video Conferencing," ACM Multimedia, 2012, pp. 159-168.

3. M. Ursu et al., "Experimental Enquiry into Automatically Orchestrated Live Video Communication," to appear in Proc. 2015 ACM Int'l Conf. Interactive Experiences for Television and Online Video (TVX), 2015.

4. J. Birringer, "Thinking Images: Paul Kaiser and Marc Downie in Conversation with Johannes Birringer," Performance, Technology \& Science, vol. 30, no. 2, 2008, pp. 17-37.

5. M. Causey, "Test of the Double: The Uncanny Performer in the Space of Technology," Theatre Journal, vol. 51, no. 4, 1999, pp. 383-394.

6. S. Dixon, Digital Performance, A History of New Media in Theatre, Dance, Performance Art, and Installation, MIT, 2007.

7. C.A. Drioli, "Networked Performances and Natural Interaction via LOLA: Low Latency High Quality AV Streaming System," 2013; www.internetsociety. org/sites/default/files/pdf/accepted/32_LOLA.pdf.

Doug Williams is a principal researcher at BT Research \& Innovation. Contact him at doug. williams@bt.com.

Ian Kegel leads the Future Content Group at BT Research \& Innovation. Contact him at ian.c.kegel@ bt.com.

Pablo Cesar leads the Distributed and Interactive Systems Group at Centrum Wiskunde \& Informatica (CWI), Amsterdam. Contact him at p.s.cesar@cwi.nl or http://homepages.cwi.nl/ garcia.

Jack Jansen is a researcher in the Distributed and Interactive Systems Group at Centrum Wiskunde \& Informatica (CWI), Amsterdam. Contact him at jack.jansen@cwi.nl.

Marian Ursu is a professor of interactive media at the University of York. Contact him at marian.ursu@york.

ac.uk.

Erik Geelhoed is a research fellow at Falmouth University. Contact him at erik.geelhoed@falmouth.ac.uk. available for free at http://ComputingNow. computer.org. 